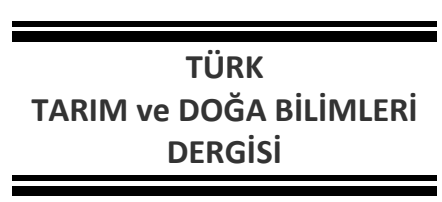

\section{Tarsus Bölgesinde Patlıcan Bitkisinin Sulama Programının CROPWAT 8.0 Programı Kullanarak Oluşturulması}

wWw.dergipark.gov.tr/turkjans

\author{
Sinan KARTAL ${ }^{1 *}$, Yeşim BOZKURT ÇOLAK ${ }^{2}$,Engin GÖNEN ${ }^{1}$, Mete ÖZFIDANER ${ }^{2}$ \\ ${ }^{1}$ Akdeniz Üniversitesi, Kumluca Meslek Yüksekokulu, Bitkisel ve Hayvansal Üretim Bölümü, 07350, Antalya \\ ${ }^{2}$ Alata Bahçe Kültürleri Araştırma Enstitüsü Müdürlüğü, Toprak ve Su Kaynakları Bölümü, Erdemli-Mersin \\ *Sorumlu yazar: sinankartal@akdeniz.edu.tr
}

Geliş Tarihi: 24.01.2019

Düzeltme Geliş Tarihi: 27.03.2019

Kabul Tarihi: 30.03.2019

\title{
Özet
}

Sulama programlanması ve bitki su tüketimi tahmini su stresinin değerlendirilmesinde ve su kaynaklarının etkin yönetilmesinde büyük önem taşımaktadır. Bitki su tüketimi hesaplamalarında toprak özellikleri, iklim parametreleri ve bitki özellikleri kullanılarak hesaplanabilmektedir. Dünyada ve ülkemizde bu işlemleri bilgisayar modelleri kullanarak hızlı ve doğru hesaplamalar yapılabilmektedir. FAO tarafından geliştirilen (Penman Monteith yöntemi) CROPWAT yazılımı kullanılarak bitki su tüketimi ve sulama yönetimi teorik veriler verilmiş ve Tarsus koşullarında 2013 ve 2014 yılları için patlıcan bitkisine ilişkin günlük ETc hesaplamaları yapılmış, en uygun koşullar ve kısıntılı sulama koşulları için sulama programları hazırlanarak verim kaybı tahminleri gerçekleştirilmiştir. Program çıktıları 2013 ve 2014 yıllarında Tarsus koşullarında patlıcan bitkisinde yürütülen bir arazi denemesinden elde edilen sonuçlar ile karşılaştırılmışır. Arazi çalışması ile CROPWAT programı 2013 yılı için 3 ve 6 gün sulama aralığında sulama suyu miktarları karşılaştıııldığında sırasıyla 496, 446 ve 432, 394 mm elde edilmiştir. 2014 yılı karşılaştıııldığında ise 3 ve 6 gün sulama aralığında sulama suyu miktarları sırasıyla 444, 396 ve 428,379 mm elde edilmiştir. Sonuçlara göre CROPWAT programı kullanılarak Tarsus bölgesinde patlıcan bitki su tüketimi ve sulama yönetimi teorik olarak elde edilen sonuçlarla uyum içerisinde olduğu görülmüştür.

Anahtar kelimeler: Bitki su tüketimi, patlıcan bitkisi, sulama programlama, Tarsus.

\section{Using CROPWAT Program for Irrigation Scheduling of Eggplant in Tarsus Region}

\begin{abstract}
Irrigation programming and evapotranspiration of importance in estimating water stress and efficient management of water resources. These calculations include complex processes based on data related to climate, soil, crop and water resources. These operations can be done quickly and accurately by using computer models in the world and our country. Our used CROPWAT software developed by FAO (Penman Monteith method), the theoretical data of evapotranspiration and irrigation management were given and daily ETc calculations for eggplant plant were made in Tarsus conditions in 2013 and 2014, and irrigation programs were prepared for optimum conditions and short irrigation conditions. The outcomes of the program were compared with the results obtained from a field trial conducted in Tarsus conditions in 2013 and 2014 in eggplant. When the irrigation water requirements of the CROPWAT program were compared with the field of irrigation water requirements in 3 and 6 days, it was found that the values of 496, 446 and 432, $394 \mathrm{~mm}$ respectively in 2013. When the irrigation water requirements of the CROPWAT program were compared with the field of irrigation water requirements in 3 and 6 days, it was found that the values of 444, 396 and 428, $379 \mathrm{~mm}$ respectively in 2014. According to the results, CROPWAT program is in harmony with the results obtained from evapotranspiration and irrigation management.
\end{abstract}

Key words: Evapotranspiration, eggplant, irrigation scheduling, Tarsus. 


\section{Giriş}

Günümüzde mevcut kullanılabilir su kaynaklarının \%74'ü tarımda kullanılmaktadır (ÇŞB, 2011). Bu nedenle tarımda suyun bilinçli kullanılması doğal kaynakların sürdürülebilir olması, yeterli ve güvenli gıda sağlanmasında önemli bir yere sahiptir. Bu kapsamda su kaynaklarından en iyi şekilde yararlanmanın temel koşulu olarak toprak, iklim ve bitki etmenlerine bağlı olan sulama zamanı ve miktarı arasındaki ilişkinin bilinmesi ve birim sudan en yüksek verimi elde edecek sulama yönteminin ve kullanılacak paket programlarının seçimi ve uygulanmasına yardımcı öğelerin geliştirilmesine ihtiyaç duyulmaktadır. Ülkemiz bulunduğu kuşaktan dolayı kurak bir iklimsel özellik göstermektedir. Bundan dolayı sulamanın, tarımsal faaliyetlerde yaygınlaştırılması son derece önem arz etmektedir. Sulama ile ilgili yapılan çalışmaların en önemli iki başlığı, kullanılacak sulama yöntemi ve sisteminin belirlenmesi olmuştur. Uygulanacak sulama yönteminin seçiminde toprağın yapısı, iklim koşulları, bitki çeşidi, sulama suyunun kalitesinin ve niceliğinin yanı sıra, ekonomik faktörlerde önemli bir yere sahiptir (Güngör ve Yıldırım 1989). Bitki su tüketimi, toprak yüzeyindeki buharlaşma ve bitkinin yapraklarında meydana gelen terlemenin toplamı alınarak, doğrudan hesaplanabildiği gibi iklimsel veriler kullanılarak tahminsel yöntemlerle de belirlenme imkânı vardır. Bitki su tüketiminin geleneksel yöntemler ile belirlenmesi, zaman kaybı ve maliyet arttırmasından dolayı, daha kısa zamanda ve düşük maliyet avantajı sağlayan ampirik eşitlikler ile tahmini edilebilmektedir. Sulama projelerinde, bitki için gerekli olan ortalama su tüketimi ve sulama zamanının belirlenmesinde genel olarak elde edilen iklimsel değerlerden tahmin yöntemi tercih edilir. Bitki için gerekli ortalama su tüketiminin belirlenmesinde uygulanan ampirik eşitlikler, genel olarak uzun periyotlar için doğru sonuçlara ulaşmamızı sağlayan ve belirli sayıda iklimsel parametre içeren eşitliklerdir. Sulama için uygun zamanın belirlenmesinde gerekli olan bitki su tüketiminin belirlenmesinde için kullanılan ampirik eşitlikler ise günlük, haftalık ve en fazla on günlük periyotlar da doğru sonuçlara ulaşmamızı sağlayan, genel olarak birden fazla iklimsel verilerinin kullanıldığı formüllerdir (Jensen, 1974; Doorenbos ve Pruitt, 1977; Burman ve ark., 1983; Orta ve ark., 2000). Bitkinin ihtiyacı olan suyun iklimsel verilere göre tahmin eşitlikleri ile hesaplanmasında, belirli iklim koşullarında referans bitki seçilerek, tahminde yapılabilmesi için tecrübelere dayalı eşitlikler oluşturulmuştur.

Elde edilen bu eşitliklerin diğer bitkiler için ihtiyacı olan gerekli su miktarının tahmin edilebilmesi için eşitliklerin, bitkinin çeşidi ve gelişmede göstereceği periyodunun fonksiyonu olan bitki katsayıları kullanılarak gerekli düzeltmeler yapılmalıdır. Referans olarak kullanılan bitkinin ihtiyacı olan suyun hesaplanmasında A sınıfı buharlaşma kabından suyun buharlaşmasını esas alan yöntem ve diğer bir yöntem olan PenmanMonteith yöntemlerine ait FAO modifikasyonu ile uzun zaman aralıkları için doğru sonuçlara ulaşamamızı sağlayacak olan Blaney-Criddle yöntemine ait FAO modifikasyonu kullanılabilir (Gürgülü ve UI, 2009).

Bitkinin su ihtiyacının belirlenmesinde toprak su bütçesi yaklaşımı son zamanda hızla gelişen bilgisayar teknolojisi ile daha da önemli hale gelmiş ve su dengesi esasını temel alan, toprak özellikleri, bitki çeşitleri ve iklimsel koşullara ek olarak sulama için seçilen yöntem ve kullanılacak olan sulama sistemine ait özelliklerini de hesaplayarak, içinde yazılımın da bulunduğu farklı simülasyon çeşitleri geliştirilmiştir. FAO‘nun geliştirmiş olduğu CROPWAT modeli ve Belçika'da bulunan K. U. Leuven Üniversitesinin yapmış olduğu çalışma ile IRSIS buna örnek olarak göstermek mümkündür. Geliştirilen bu modeller sayesin de sulama için uygun zamanın belirlenmesinde iklimsel etkiler, bitkiden kaynaklı ve toprakla alakalı olan veriler ile seçilmiş sulama yöntemi ve belirlene sulama sisteminin bilgilerinden yararlanılır (Kodal ve ark., 1993). Bitkiler için uygun olan sulama zamanının belirlenmesi maksadı ile geliştirilen bu yazılım programlarından yararlanılarak farklı iklimsel özellikler, farklı toprak özellikleri ve kullanılacak olan suyun kaynağının yeterli olup olmamasına göre, bitkinin sulama zamanının tespiti farklı seçenekler ile kısa süre zarfında mümkün olmaktadır (İstanbulluoğlu ve Şişman, 2004).

Tarsus bölgesinde yaygın olarak yetiştiriciliği yapılan patlıcan bitkisinin sulama programının oluşturulması büyük önem taşımaktadır. Bu çalışmada Tarsus bölgesinde 2013 ve 2014 yıllarında hesaplamaları yapılan patlıcan bitkisinde ET ve sulama suyu miktarı, mevcut toprak, iklim ve bitki faktörlerine göre CROPWAT bilgisayar yazılımı kullanarak hesaplamalarının karşılaştırılması yapılarak bölgede patlıcan üreticilerine sulama programının önerilebilmesi amaçlanmıştır.

\section{Materyal ve Yöntem \\ CROPWAT modeli}

CROPWAT 8.0 modeli, 1992 yılında FAO Arazi ve Su Geliştirme Bölümü tarafından geliştirilmiştir. Tarımsal meteorologların, tarım uzmanlarının ve sulama mühendislerinin referans bitki su tüketimi ve mahsul bitki su tüketimi hesaplamalarına yardımcı olmak için tasarlanmıştır. Model ayrıca sulama yöntemlerinin iyileştirilmesi, farklı sulama koşullarında sulama programlarının planlanması ve yağmur suyu koşullarının veya yeterli sulama 
koşullarının bitki verimi üzerindeki etkilerinin değerlendirilmesi konusunda önerilerde bulunabilmektedir. CROPWAT modeli için gerekli giriş parametreleri meteorolojik parametreler, ürün parametreleri ve toprak parametrelerini içermektedir. Meteorolojik parametreler: sıcaklık, yağış, rüzgâr hızı, güneşli saatler, bağıl nem oluşturmaktadır. Ürün parametreleri, ekim ve hasat tarihi, bitki katsayısı, kök uzunluğu ve bitki faktörünü içermektedir. Toprak parametreleri: toprak tekstürü, mevcut toprak suyu, sızma oranı ve ekim tarihindeki toprak suyu miktarını oluşturmaktadır. CROPWAT modeli aşağıda verilen temel işlevleri hesaplayabilmektedir:

(1) Referans bitki su tüketimi;

(2) Bitki su tüketimi;

(3) Bitkinin sulama suyu ihtiyacını;

(4) Sulama sisteminin geliştirilmesi;

(5) Yağmur veya yetersiz sulamanın verime olan etkisinin değerlendirilmesi.

Ek olarak, CROPWAT modeli kullanılarak günlük su bütçesi analizi yapılabilir.

Programda referans bitki su tüketiminin hesaplanmasında Eşitlik 1'de verilen FAO PenmanMonteith yöntemi esas alınmaktadır.
ETO $=$
$0,480 \Delta(R n-G)+\gamma \frac{900}{T+273} U 2(e a-e d)$
$\Delta+\gamma(1+0.34 U 2)$

Eto: Bitki Su Tüketimi, Mm/D.

$R n$ : Net Radyasyon, $\mathrm{MJ} /\left(\mathrm{M}^{2} \cdot \mathrm{D}\right)$.

$G$ : Soil Heat Flux, MJ/(M $\left.{ }^{2} \cdot D\right)$.

$T$ : Ortalama Hava Sıcaklığı, ${ }^{\circ} \mathrm{C}$.

$U_{2}: 2 \mathrm{~m}$ Yükseltideki Rüzgar Hızı, M/S;

$\left(E_{a}-E_{d}\right)$ : Buhar Baıncı Açığı, Kpa.

$\Delta$ : Buhar Basıncı Eğrisinin Eğimi, $\mathrm{Kpa} /{ }^{\circ} \mathrm{C}$.

Г: Psikometrik Katsayı, Kpa/ ${ }^{\circ} \mathrm{C}$.

Programda bitki su tüketiminin

hesaplanmasında Eşitlik 2 kullanılarak

hesaplanmıştır.

$$
E T c=K c X E T 0
$$

Etc: Bitki su tüketimi.

Kc: Bitki katsayısı.

$\mathrm{ET}_{0}$ : Referans bitki su tüketimi.

\section{Araştırma yılı iklim verileri}

İklim verisi olarak aylık en yüksek sıcaklık (Tmax), en düşük sıcaklık (Tmin), ortalama oransal nem (RH), rüzgar hızı (u2), güneş radyasyonu (Rs), yağış verileri kullanılmıştır Ardından iklim istasyonu olarak veri tabanına Tarsus enlem, boylam ve yükselti değerleri girilmiştir 2013 ve 2014 yılı iklim ve yağış verileri (Şekil 1, 2, 3 ve 4).

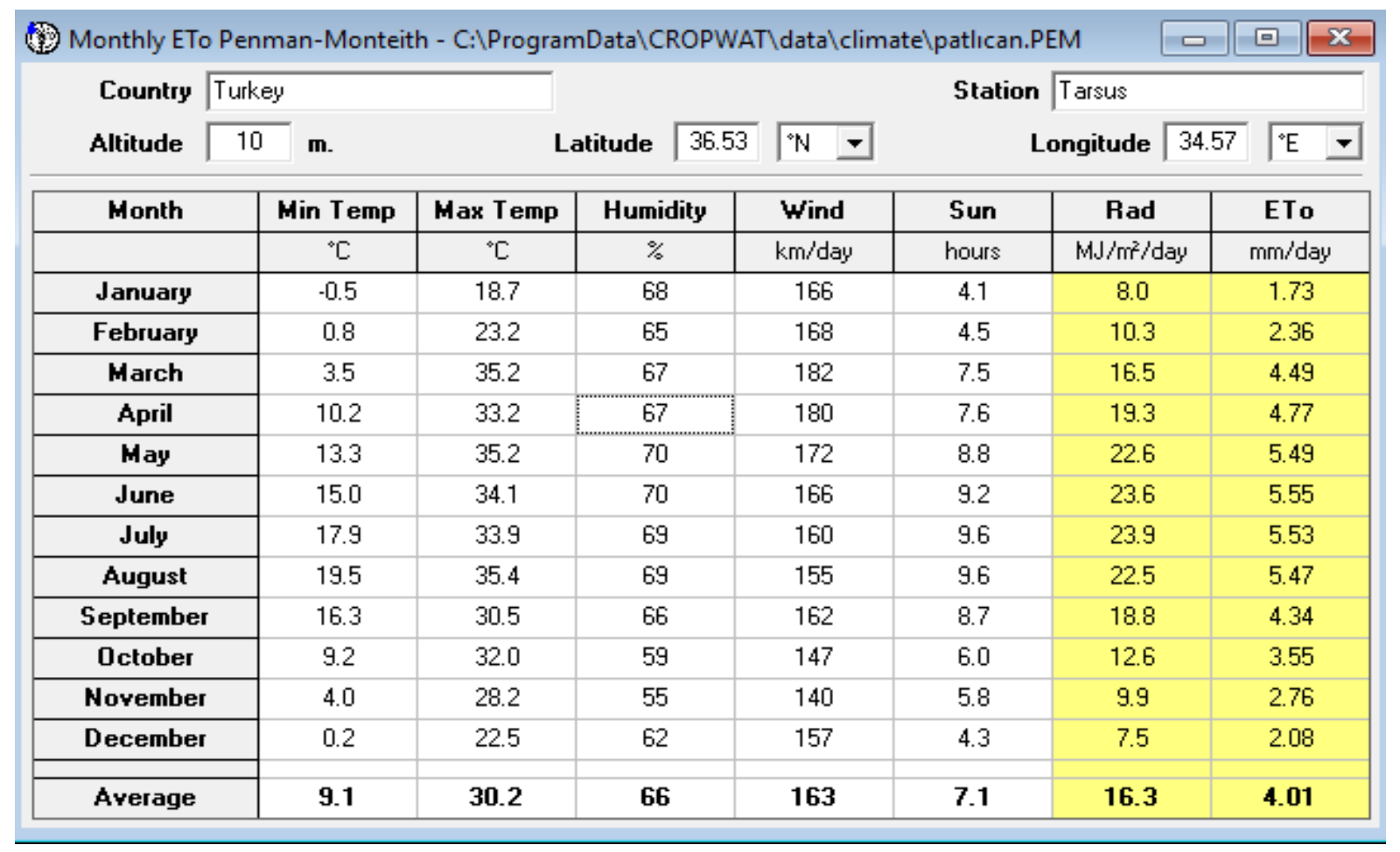

Şekil 1. 2013 yılı iklim verileri. 
(1)

Monthly rain - C:IProgramData\CROPWAT\datałrain \patlıcan.CRM

\begin{tabular}{|c|c|c|}
\hline & Rain & Eff rain \\
\hline & $\mathrm{mm}$ & $\mathrm{mm}$ \\
\hline January & 33.1 & 31.3 \\
\hline February & 28.0 & 26.7 \\
\hline March & 22.5 & 21.7 \\
\hline April & 20.0 & 19.4 \\
\hline May & 25.0 & 24.0 \\
\hline June & 6.0 & 5.9 \\
\hline July & 10.0 & 9.8 \\
\hline August & 0.0 & 0.0 \\
\hline September & 9.0 & 8.9 \\
\hline October & 13.0 & 12.7 \\
\hline November & 32.0 & 30.4 \\
\hline December & 30.0 & 28.6 \\
\hline \hline Total & $\mathbf{2 2 8 . 6}$ & $\mathbf{2 1 9 . 4}$ \\
\hline
\end{tabular}

Şekil 2. 2013 yılı yağış verileri.

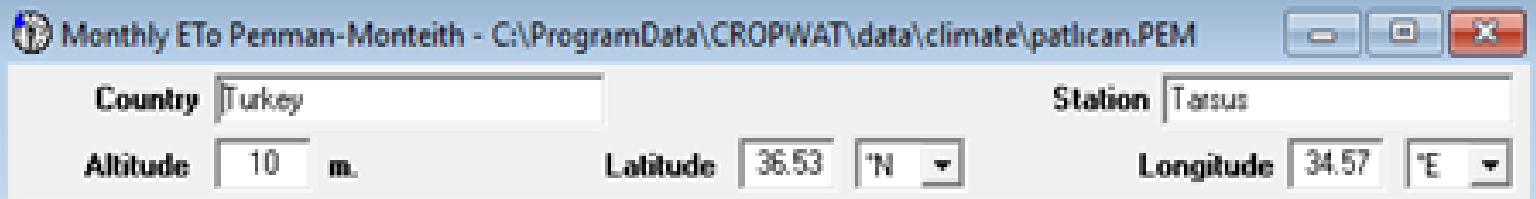

\begin{tabular}{|c|c|c|c|c|c|c|c|}
\hline Month & Min Temp & Max Temp & Humidity & Wind & Sun & Rad & ETo \\
\hline & ${ }^{4} \mathrm{C}$ & ${ }^{\circ} \mathrm{C}$ & $x$ & $\mathrm{~km} / \mathrm{d} \alpha \mathrm{g}$ & hours & MN/nt/doy & $\mathrm{men} / \mathrm{d} s y$ \\
\hline Januaty & 0.5 & 19.0 & 68 & 168 & 3.9 & 7.8 & 1.76 \\
\hline Februaty & 0.8 & 225 & 65 & 167 & 5.4 & 11.2 & 241 \\
\hline March & 3.5 & 24.7 & 63 & 184 & 6.8 & 15.6 & 330 \\
\hline April & 4.4 & 34.2 & 66 & 183 & 7.7 & 19.4 & 500 \\
\hline May & 126 & 34.6 & 70 & 171 & 8.2 & 21.7 & 6.69 \\
\hline June & 17.8 & 38.2 & 71 & 166 & 9.6 & 24.2 & 6.11 \\
\hline July & 21.6 & 32.9 & 70 & 159 & 9.6 & 23.9 & 5.48 \\
\hline August & 21.1 & 39.2 & 69 & 156 & 9.6 & 22.5 & 593 \\
\hline September & 16.1 & 34.5 & 65 & 167 & 8.8 & 19.0 & 4.88 \\
\hline October & 9.7 & 32.5 & 57 & 145 & 6.2 & 12.8 & 367 \\
\hline Novembet & 4.4 & 28.0 & 57 & 138 & 6.2 & 10.3 & 271 \\
\hline Decembet & 0.0 & 21.2 & 65 & 156 & 4.4 & 7.6 & 1.92 \\
\hline Average & 9.3 & 30.1 & 60 & 163 & 7.2 & 16.3 & 4.15 \\
\hline
\end{tabular}

Şekil 3. 2014 yılı iklim verileri. 


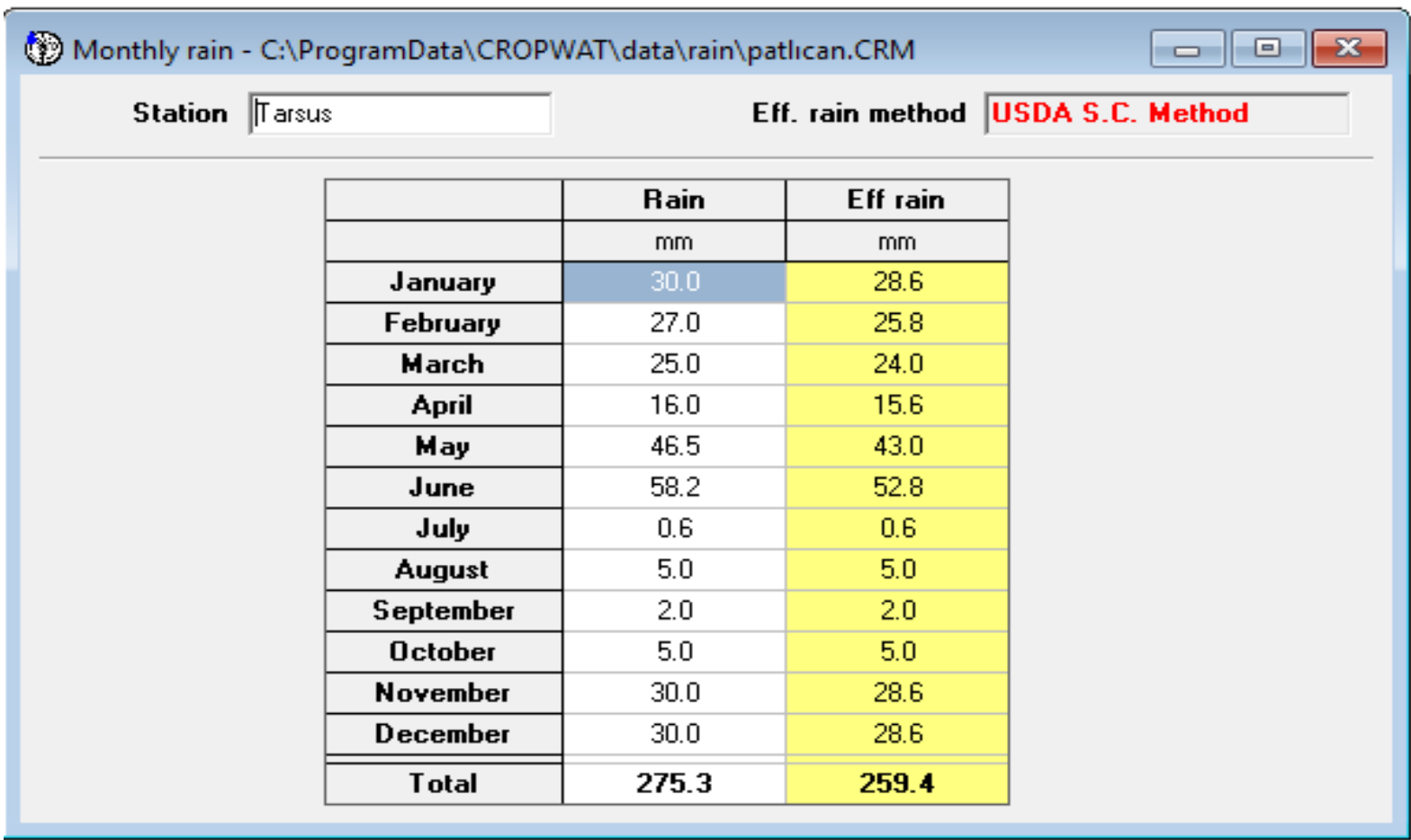

Şekil 4. 2014 yılı yağış verileri.

\section{Araştırma yerinin toprak özellikleri}

$\mathrm{Bu}$ hesaplama için $90 \mathrm{~cm}$ 'lik bir toprak profilinin fiziksel özellikleri Bozkurt Çolak (2017)'de (Çizelge 1) verilen toprak özelliklerine göre hacim ağırlığı $1,4 \mathrm{~g} / \mathrm{cm}^{3}$, ağırlık yüzdesi cinsinden tarla kapasitesi \% 29.64 ve solma noktası \%19.09 olarak sisteme girilmiştir (Şekil 5).

Çizelge 1. Deneme yeri topraklarının bazı fiziksel özellikleri

\begin{tabular}{cccccccc}
\hline $\begin{array}{c}\text { Derinlik } \\
(\mathbf{c m})\end{array}$ & $\begin{array}{c}\text { Kum } \\
(\%)\end{array}$ & $\begin{array}{c}\text { Kil } \\
(\%)\end{array}$ & $\begin{array}{c}\text { Silt } \\
\mathbf{( \% )}\end{array}$ & Bünye & $\begin{array}{c}\text { Tarla kapasitesi (g } \\
\mathbf{g}^{-\mathbf{1}} \mathbf{)}\end{array}$ & $\begin{array}{c}\text { Solma noktası } \\
\left(\mathbf{g ~ g}^{-\mathbf{1}}\right)\end{array}$ & $\begin{array}{c}\text { Hacim ağırlı̆̆ }(\mathbf{g} \\
\left.\mathbf{c m}^{-3}\right)\end{array}$ \\
\hline $0-20$ & 20.2 & 41.9 & 37.9 & $\mathrm{C}$ & 29.92 & 19.14 & 1.30 \\
$20-40$ & 15.9 & 42.0 & 42.1 & $\mathrm{SiC}$ & 29.77 & 18.95 & 1.40 \\
$40-60$ & 11.7 & 44.1 & 44.3 & $\mathrm{SiC}$ & 29.64 & 19.09 & 1.42 \\
$60-90$ & 11.1 & 42.2 & 46.7 & $\mathrm{SiC}$ & 29.40 & 19.71 & 1.45 \\
\hline
\end{tabular}

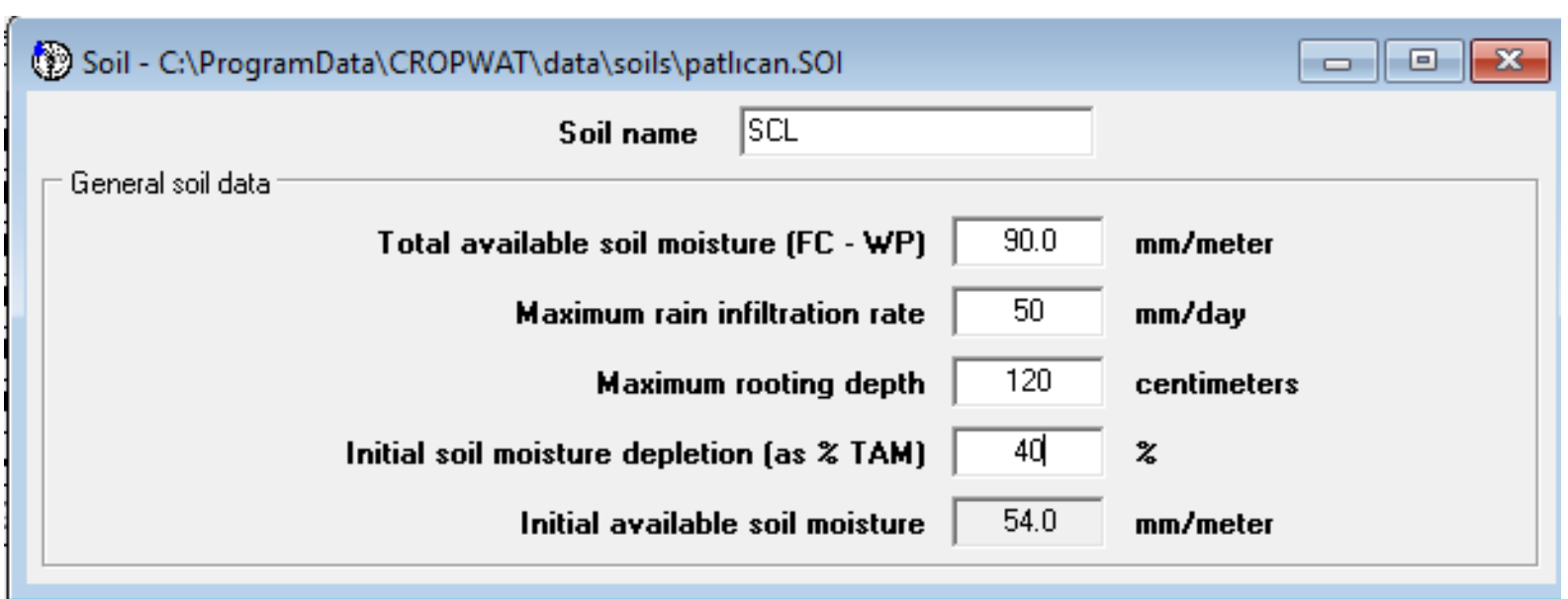

Şekil 5. Programda gerekli olan toprak özellikleri.

\section{Patlıcan bitkisinin özellikleri}

Tarsus bölgesi için patlıcan bitki katsayısı değerleri başlangıç, orta ve son dönem için sırasıyla $0.52,1.00$ ve 0.84 (Anonim, 2017) olarak programa girilmiştir. Aynı ara yüzde başlangıç, gelişme, orta ve son dönem uzunlukları sırasıyla 20, 30, 30 ve 20 gün ve patlıcan bitkisinin etkili kök derinliği ekim için 10 $\mathrm{cm}$ ve orta dönem başlangıcı itibari ile $60 \mathrm{~cm}$ olarak 
sisteme girilmiştir. Kritik seviye değeri 0.45 ve Ky değeri 1,1 olarak dikkate alınmıştır. Söz konusu dosya ETc ve sulama programlama işlemleri için hazır hale getirilmiştir. Bitki dikim tarihi olarak 06 Mayıs 2014 girilmiştir (Şekil 6).

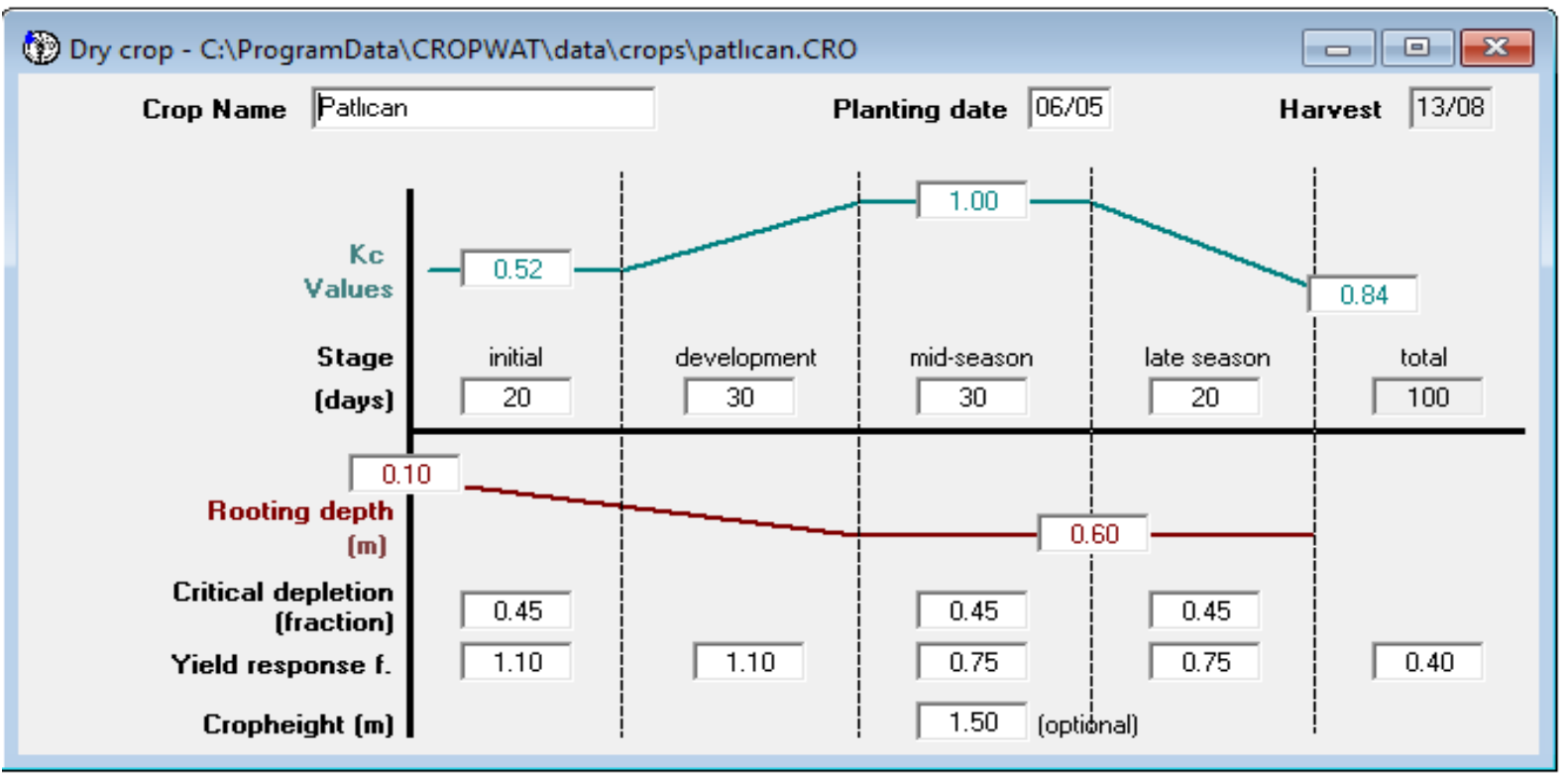

Şekil 6. Program için gerekli olan patlıcan bitkisinin değerleri.

Bu çalışmada CROPWAT 8.0 yazılımı bitki su tüketimi ve sulama yönetimi modülü kullanılarak hazırlanan örnek çözüm sonuçları Bozkurt Çolak ve ark. (2017)' de detayları verilen patlıcan bitkisinde ETc ve verim sonuçları ile karşılaştırılmıştır. Bu nedenle örnek çözümde Tarsus ilçesinin 2014 yılı iklim verileri, patlıcan bitkisinin özellikleri, sulama yöntemi olarak damla sulama yöntemi ve söz konusu araştırmanın yapıldığı deneme arazisinin toprak özellikleri kullanılmıştır. Program için gerekli olan veriler önce Ms Excel ortamında düzenlenmiş ve eksik olan veriler Allen ve ark. (1998)' de verilen yöntemlere göre tamamlanarak, her bir verinin bulunduğu modüle veri tabanı formatı ile aynı olacak şekilde aktarılmıştır. Ardından sulama suyu miktarları ve mevsimlik bitki su tüketim değerlerinin hesaplamaları yapılmıştır. Hesaplamanın ardından elde edilen sonuçlar, genel olarak kontrol edilmiştir. Gerekli bilgiler CROPWAT programına girildikten sonra sulama planlaması yapılmıştır. Sulama yöntemi olarak damla sulama seçilmiş, sulama randımanı \%90 olarak sisteme girilmiştir.

\section{Bulgular ve Tartışma}

CROPWAT sistemi verim kaybının olmayacağı en uygun sulama programı kapsamında, Tarsus' da 2013 yılında, damla sulama ile sulanan patlıcan bitkisinde 27 defa sulama öngörmüş, net sulama suyu miktarı $424 \mathrm{~mm}$, mevsimlik ETc'nin ise $454.4 \mathrm{~mm}$ olarak hesaplamıştır (Şekil 7), 2014 yılında ise 24 defa sulama öngörmüş, net sulama suyu miktarı $447.8 \mathrm{~mm}$, mevsimlik ETc'nin ise 474 $\mathrm{mm}$ olarak hesaplamıştır (Şekil 8).
En uygun sulama programının yanı sıra, sistemin test edilmesi için sabit sulama aralığı 3 ve 6 gün için ayrı ayrı sulama programları hazırlanmıştır. Konu edilen 2 farklı sulama programına ilişkin grafiksel sonuçlar 2013 ve 2014 yılları için aşağıda verilmiştir (Şekil 9, 10, 11 ve 12). Şekil üzerinde her bir sulama programı için CROPWAT sistemi tarafından hesaplanan mevsimlik toplam sulama suyu miktarı, ETc ve verim kaybı yüzdesi değerleri de verilmiştir.

Bozkurt Çolak (2017)' da verildiğine göre, Tarsus' da 2013 ve 2014 yıllarında tam sulama koşulunda damla sulama ile sulanan patlıcan bitkisinde ile 3 ve 6 gün sulama aralığında mevsim boyunca sırasıyla 496, 446 ve 444, $396 \mathrm{~mm}$ net sulama suyu uygulanmış ve ölçülen verilerle yapılan toprak su bütçesi hesabı sonucunda ETc yine sırasıyla 543, 527 ve 527, $508 \mathrm{~mm}$ olarak elde edilmiştir. CROPWAT programı kullanılarak 2013 yılı iklim verilerine göre 3 ve 6 gün sulama aralığında sırasıyla 432 ve $394 \mathrm{~mm}$ toplam sulama suyu uygulanacağı patlıcan yetişme mevsimindeki yağışlarla birlikte sırasıyla toplam yine sırasıyla 454 ve $438 \mathrm{~mm}$ ETc oluşabileceği tahmin edilmiştir. 2014 yılı iklim verilerine göre ise 3 ve 6 gün sulama aralığında sırasıyla 428 ve $379 \mathrm{~mm}$ toplam sulama suyu uygulanacağı patlıcan yetişme mevsimindeki yağışlarla birlikte sırasıyla toplam 476 ve $457 \mathrm{~mm}$ ETc oluşabileceği tahmin edilmiştir (Çizelge 2). Program çıktıları arazi çalışması sonuçları ile benzerlik göstermektedir. 


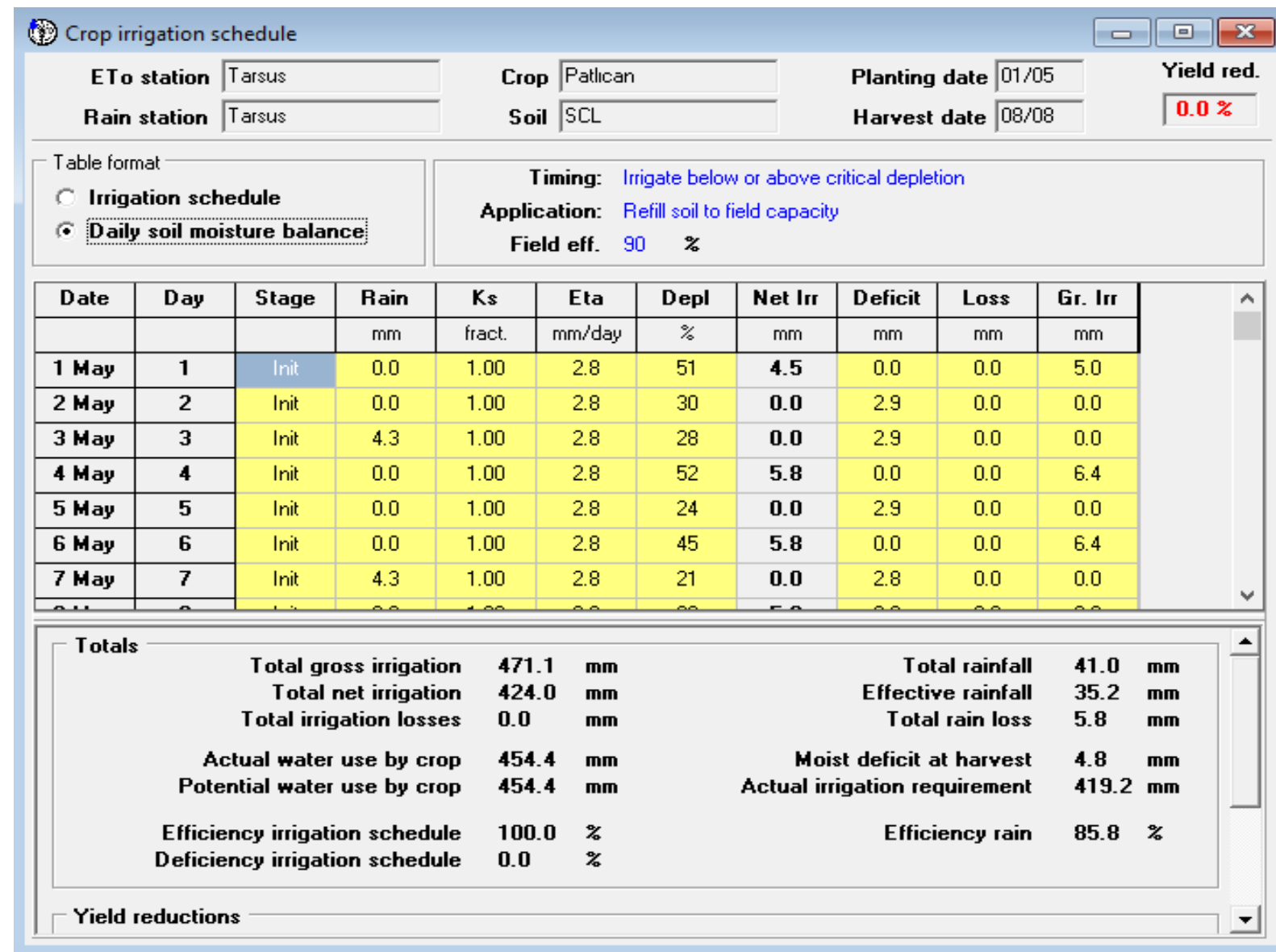

Şekil 7. CROPWAT, Tarsus 2013 yılı iklim verileri kullanılarak tam sulama sonuçları.

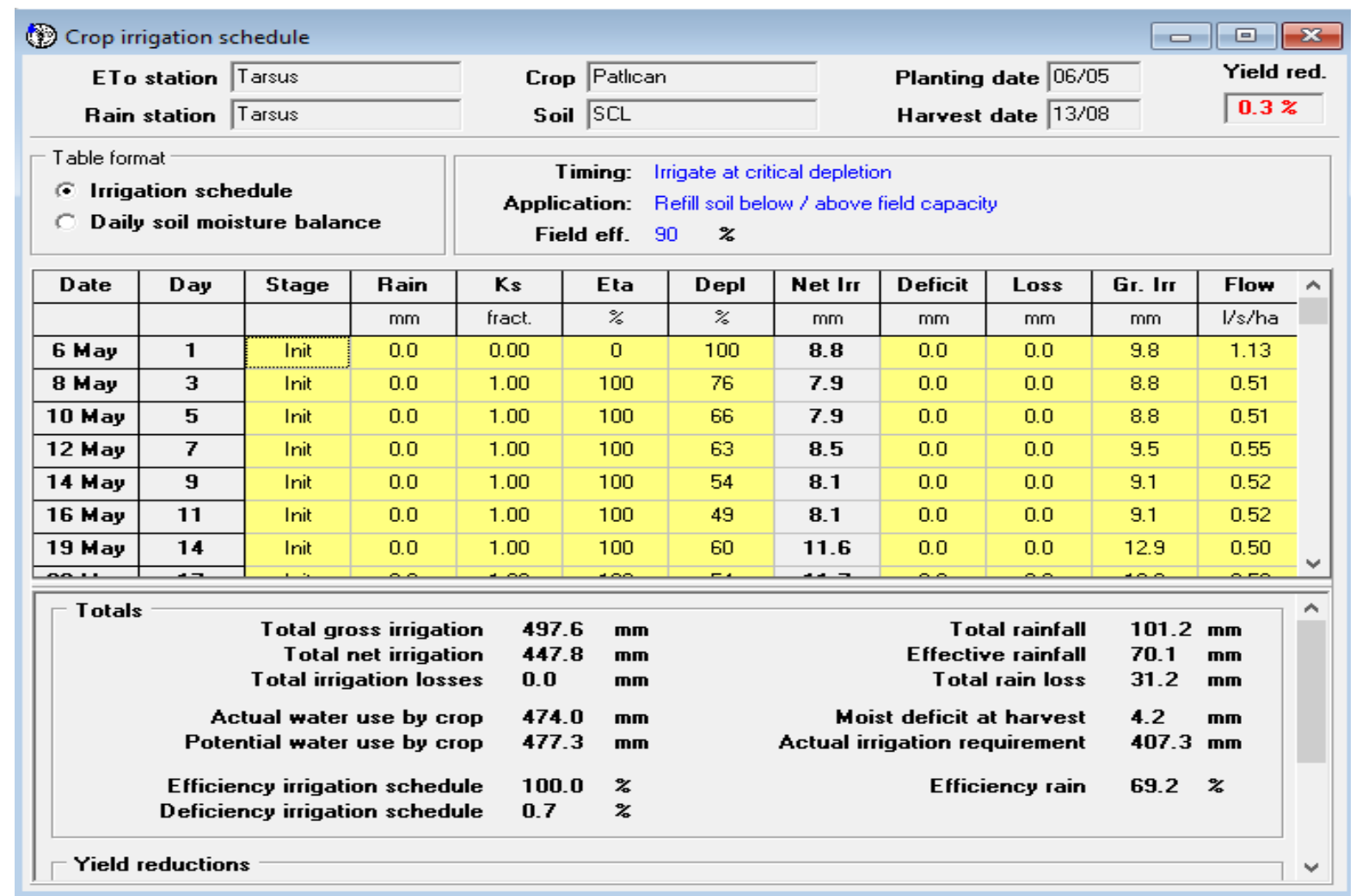

Şekil 8. CROPWAT, Tarsus 2014 yılı iklim verileri kullanılarak tam sulama sonuçları. 


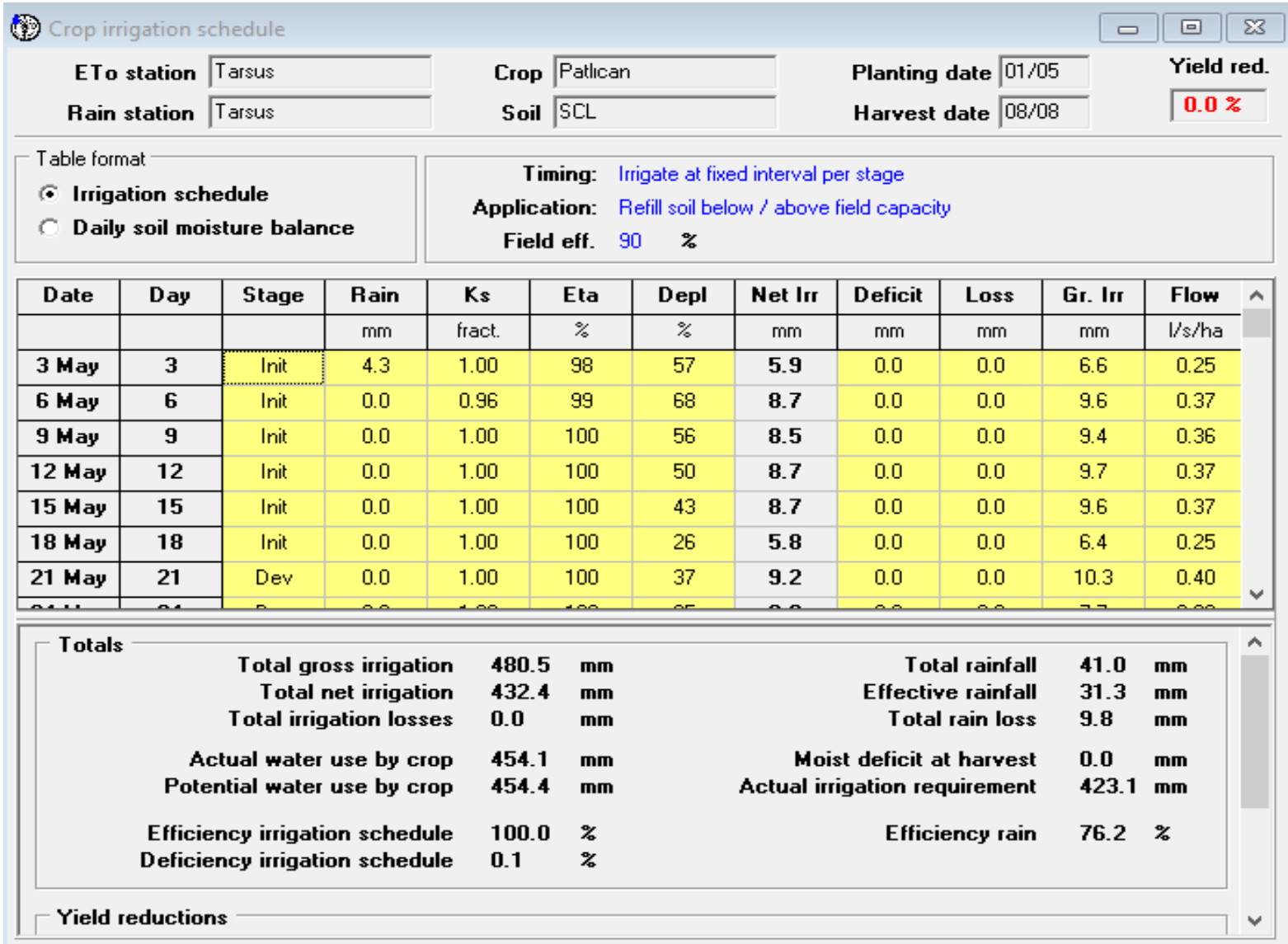

Şekil 9. CROPWAT, Tarsus 2013 yılı iklim verileri kullanılarak yetişen patlıcan bitkisi için 3 gün sulama aralığında sulama suyu miktarları.

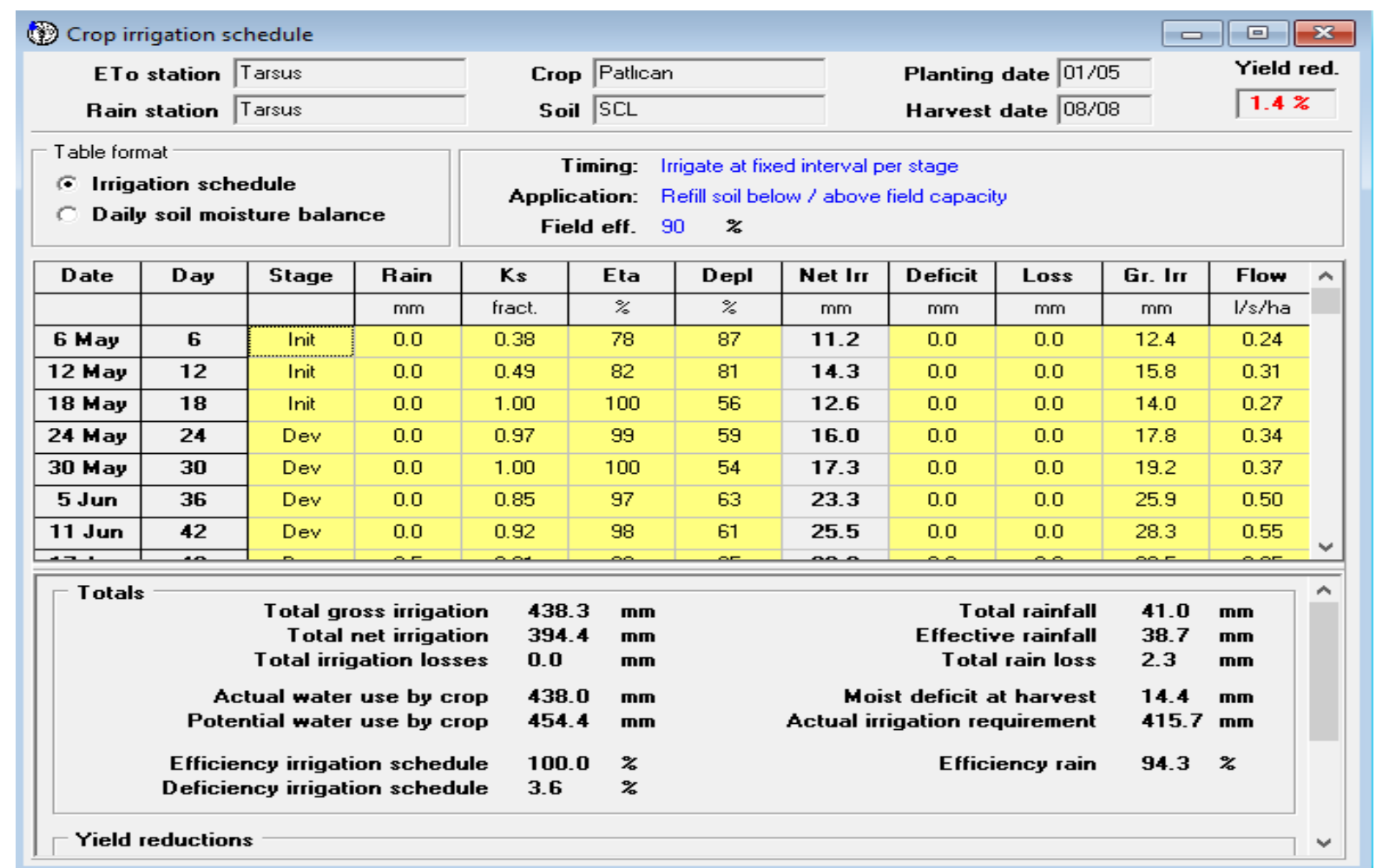

Şekil 10. CROPWAT, Tarsus 2013 yılı iklim verileri kullanılarak yetişen patlıcan bitkisi için 6 gün sulama aralığında sulama suyu miktarları. 


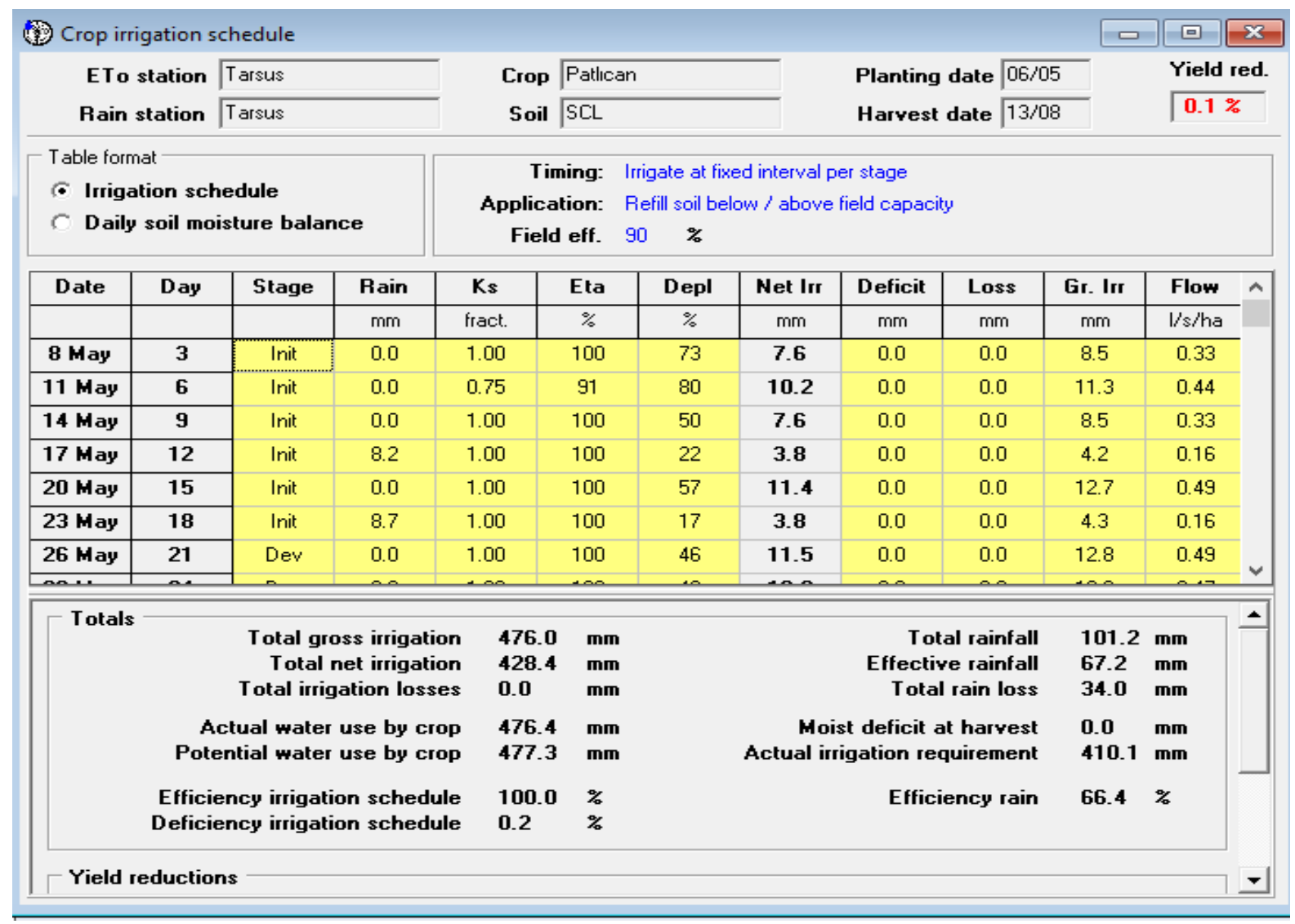

Şekil 11. CROPWAT, Tarsus 2014 yılı iklim verileri kullanılarak yetişen patlıcan bitkisi için 3 gün sulama aralığında sulama suyu miktarları.

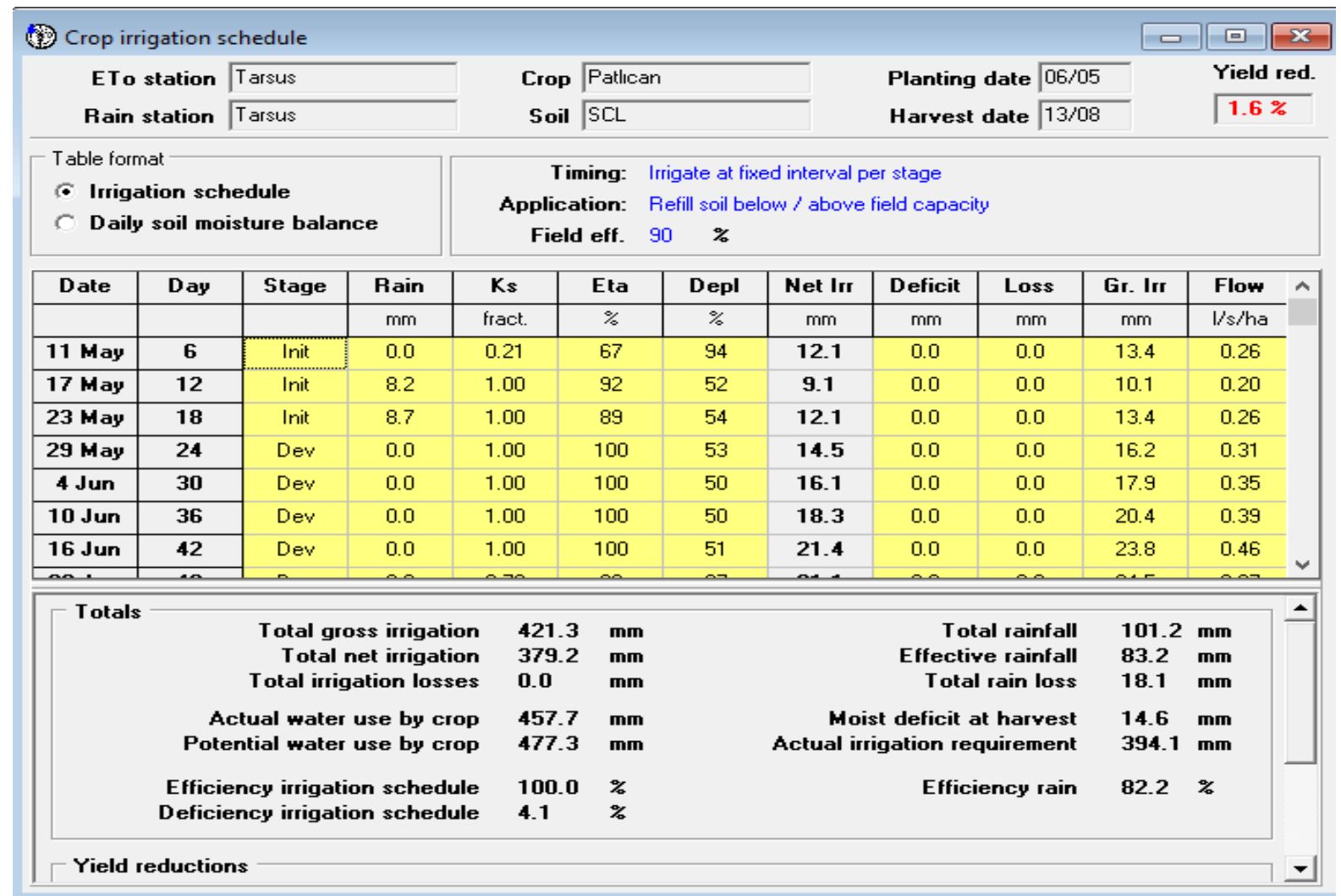

Şekil 12. CROPWAT, Tarsus 2014 yılı iklim verileri kullanılarak yetişen patlıcan bitkisi için 6 gün sulama aralığında sulama suyu miktarları. 
Çizelge 2. CROPWAT ile arazi denemesinin karşılaştırılması

\begin{tabular}{cccc}
\hline Konular & Sulama Aralıkları & Sulama suyu miktarı $(\mathbf{m m})$ & Bitki su tüketimi $(\mathbf{m m})$ \\
\hline \multirow{2}{*}{2013 deneme yılı } & 3 gün & 496 & 543 \\
& 6 gün & 446 & 527 \\
\hline \multirow{2}{*}{2014 deneme yılı } & 3 gün & 444 & 527 \\
& 6 gün & 396 & 508 \\
\multirow{2}{*}{ CROPWAT 2013 } & 3 gün & 432 & 454 \\
& 6 gün & 394 & 438 \\
\hline \multirow{2}{*}{ CROPWAT 2014 } & 3 gün & 428 & 476 \\
& 6 gün & 379 & 457 \\
\hline
\end{tabular}

Balçın ve Güleç, (1997), sulama programlanmasında kullanılmak amacı ile geliştirilmiş olan CROPWAT (7.0) ile IRSIS paket programı yardımı ile hesaplanan en uygun olarak planlanan sulama sonuçları ile tarla denemelerindeki bulunan değerler kıyaslanmıştır. "Class A Pan" (A Sınıfı Buharlaşma Kabı) yöntemi kullanılarak domates bitkisinin sulamasını programlanması maksadıyla 1994-1996 yıllarına arasındaki yapılan tarla denemesinden elde edilen sonuçlar karşılaştırma amacı ile kullanılmıştır. Yapılan karşılaştırmaya göre, IRSIS ile CROPWAT paket programlarında hesaplanan sulama sayısı ve kullanılan sulama suyu miktarı, yapılan tarla denemelerindeki sonuçlara yakın bulunmuştur. Memon ve Jamsa (2018), Hindistan'da FAOCropwat 8.0 yazılımını kullanarak domates ve soya fasulyesinin bitki su ihtiyacını belirlemişlerdir. Çalışmada sulama programlamasında minimum verim kaybında en iyi sulama programını kritik sulama modülünde elde etmişlerdir. Dünyada CROPWAT programı kullanarak sulama programlamasında ve bitki su tüketimi hesaplamalarında kullanılabileceği birçok araştırmacı tarafından bildirilmiştir (Cai ve ark., 2007; Lo'pez-Urrea ve ark., 2012; Dong, 2018; Memon ve Jamsa, 2018). Bu nedenle bölge iklim ve toprak koşullarında yaygın olarak yetiştiriciliği yapılan patlıcan bitkisinde üreticilere CROPWAT programı kullanılarak etkin bir sulama programı oluşturulabileceği görülmektedir.

Sulama programlamasında bitki su tüketimi (ET), suyun en fazla kullanıldığı tarım sektöründe son zamanlarda sulama suyu hesabı ve kuraklığın izlenmesi ve değerlendirilmesi başta olmak üzere birçok konuda kullanılan önemli bir parametredir. ET bölge şartlarını temsil eden iklimsel koşullar, bitki, toprak özellikleri, seçilen sulama yöntemi ve su varlığına dayanmaktadır. Sulama için yapılan programlar hem sulama sistemlerinin tasarımı hem de sulama sistemlerinin işletilmesi için büyük öneme sahiptir. Bu amaçla geliştirilen bilgisayar yazılımları kullanılarak bitki su tüketim hesaplamaları ve sulama programlaması gerçekleştirilebilmektedir. Bu program farklı sulama programlaması yapılabildiğinden en az verim kaybının ve optimum sulama suyu miktarının hesaplanmasında kullanılabilmektedir.

\section{Sonuç ve Öneriler}

Bu çalışmada CROPWAT yazılımı kullanılarak, Tarsus koşullarında patlıcan bitkisinde en uygun sulama programlamasının belirlenmesi, 2013 ve 2014 yıllarında patlıcan bitkisi üzerine yürütülen bir arazi denemesi sonuçlarının program ile karşılaştırılması yapılmıştır. CROPWAT programı verim kaybı olmadan en uygun sulama programını kritik seviye sulama modülünde elde etmiştir. Arazi çalışmalarının ise program çıktıları ile benzerlik gösterdiği görülmüştür. Sonuçta CROPWAT programının sulama programlamasında ve bitki su tüketim hesaplamaları tahmininde yararlanılabileceği ancak program için gerekli olan girdilerin doğru bir şekilde belirlenmesi gerektiği görülmektedir.

\section{Kaynaklar}

Allen, R.G., Pereira, L.S., Raes, D., Smith, M. 1998. Crop Evapotranspiration: Guidelines for Computing Crop Water Requirements. Irrigation and Drainage Paper 56. Food and Agriculture Organization of the United Nations, Rome.

Anonim, 2017. Türkiye'de Sulanan Bitkilerin Bitki Su Tüketimleri. Gıda Tarım ve Hayvancılık Bakanlığı. ISBN:978-605-9175-3-7, 74 s.

Balçın, M., Güleç, H. 1997. IRSIS ve CROPWAT paket programından elde edilen sulama programlarının tarla sartlarında elde edilen sulama programları ile karşılaştırılması. 6. Ulusal Kültürteknik Kongresi, 5-8 Haziran 1997, Uludağ Üniversitesi Ziraat Fakültesi ve Kültürteknik Derneği, Kirazlıyayla- Bursa.

Bozkurt Çolak, Y., Yazar, A., Sesveren, S., Colak, I. 2017. Evaluation of yield and leaf water potential (LWP) for eggplant under varying irrigation regimes using surface and subsurface drip systems. Scientia Horticulturae, 219: 10-21. 
Burman, R.D., Nixon, P.R., Wright, J.L., Pruitt, W.O. 1983. Water Requirements Design and Operation of Farm Irrigation Systems. 829 p.

Çakmak, B., Kendirli, B. 2001. Gediz Havzası'nda Zeytinin Sulanması ve Ekonomik Yönü. Ankara Üniversitesi Ziraat Fakültesi Tarımsal Yapılar ve Sulama Bölümü.

Cai, J., Liu, Y., Lei, T., Pereira, L.S. 2007. Estimating reference evapotranspiration with the FAO Penman-Monteith equation using Daily weather forecast messages. Agr.Forest Meteorol., 145: 22-35.

ÇŞB, 2011. Türkiye Çevre Durum Raporu. Çevre ve Şehircilik Bakanlığı, 2011, Ankara.

Dong, Q. 2018. IOP Conf. Ser.: Mater. Sci. Eng. 394 022037, pp.1-6.

Doorenbos, J., Pruitt, W.O. 1977. Guidelines for Predicting Crop Water Requirements. FAO Irrigation and Drainage Paper, No: 24.

Güngör, Y., Yıldırım, O. 1989. Tarla Sulama Sistemleri. Ankara Üniv. Zir. Fak. Yayınları, No: 155, 371 s., Ankara.

Gürgülü, H. , Ul, M.A. 2009. Manisa ve İzmir'e ait referans bitki su tüketimi değerlerinden yararlanarak bağ için maksimum bitki su tüketiminin hesaplanması. 7. Bağcılık ve Teknolojileri Sempozyumu, 5-9 Ekim 2009, Poster Bildiri, s. 78, Salihli-Manisa.

İstanbulluoğlu, A., Şişman, C.B. 2004. Tekirdağ Ziraat Fakültesi Tarım arazilerinin sulama zamanının model yaklaşımı ile planlanması. Trakya Üniversitesi Fen Bilimleri Dergisi, 5(1): 35-41.

Jensen, M.E. 1974. Consumptive Use of Water and Irrigation Water Requirements. ASCE, New York, USA, 215 p. Kitabı: 493.

Kodal, S., Yıldırım, E., Dağdelen, N. 1993. Tarımsal Kuraklık ve Sulama İhtiyacı. Kuraklık ve Sulama Sempozyumu, Türkiye Ziraat Odaları Birliği, 27 Nisan 1993, Yayın No: 172, Ankara.

López-Urreaa, R., Montoroa, A., Ma nasa, F., LópezFustera, P., Fereres, E. 2012 Evapotranspiration and crop coefficients from lysimeter measurements of mature 'Tempranillo' wine grapes. Agric. Water Manage., 112: 13-20.

Memon, A.V., Jamsa, S., 2018. Crop water requirement and irrigation scheduling of soybean and tomato crop using CROPWAT 8.0. International Research Journal of Engineering and Technology (IRJET) e-ISSN: 2395-0056, 5(9): 669-671.

Orta, A.H., Yüksel, A.N., Erdem, T. 2000. Tekirdağ Koşullarında farklı sulama yöntemlerinin elma ağaçlarının su tüketimine etkisi. Tarım Bilimleri Dergisi, 6(3): 109-115. 